Çukurova Üniversitesi Mühendislik Mimarlık Fakültesi Dergisi, 35(4), ss. 1001-1007, Aralık 2020

Çukurova University Journal of the Faculty of Engineering and Architecture, 35(4), pp. 1001-1007, December 2020

\title{
Ç2842, MS58 ve Al 6013 Malzemelerin Elektolitik Ni Kaplanmasında Kaplama Kalınlığı ve Yüzeysel Özelliklerin İncelenmesi
}

\author{
Harun KOÇAK ${ }^{* 1}$ \\ ${ }^{1}$ Gazi Üniversitesi, Tusaş Kazan MYO, Motorlu Araçlar ve Ulaştırma Teknolojileri Bölümü, \\ Ankara
}

Geliş tarihi: 02.11 .2020

Kabul tarihi: 30.12 .2020

$\ddot{\mathbf{O z}}$

Bu çalışmada elektolitik Ni kaplanmada Ç2842, MS58 ve Al 6013 malzemelerin etkisi ve kaplama sonrası yüzey pürüzlülüğünün değişimi incelenmiştir. Deneylerde Ç2842 çelik, MS58 pirinç ve Al 6013 alüminyum alaşımı malzemeler $\mathrm{Ni}$ ile kaplanmıştır. $\mathrm{Bu}$ malzemeler, torna tezgahında farklı ilerleme oranlarında $(0,065-0,13 \mathrm{~mm} / \mathrm{dev})$ işlenerek numuneler üzerinde farklı yüzey pürüzlülükleri elde edilmiştir. Daha sonra numuneler üzerine Ni kaplanmıştır. Kaplama işlemi sonrasında kaplama kalınlığ ve kaplama sonrası yüzey pürüzlülügü ölçülmüş görüntülü incelmeler yapılarak kaplama kalitesi incelenmiştir. Deneyler sonucunda, diğer malzemelere göre MS 58 malzeme üzerinde daha kalın Ni tabakası $(43 \mu \mathrm{m})$ elde edilmiştir. Kaplanan malzemenin elektriksel iletkenliğinin yüksek olması kaplama hızını arttırmaktadır. Ancak iletkenlik değerinin düşük olması kaplama yüzeyinin kalitesini iyileştirmektedir. Çelik malzemenin kaplama sayesinde yüzey pürüzlülüğü değeri \%33-57 aralığında azalmıştır. Al 6013 malzemede, kaplama sonrası yüzey pürüzlülüğü \%94-107 oranında artmakla beraber çukur şeklinde yüzeysel hatalar ortaya çıkmaktadır.

Anahtar Kelimeler: Elektrolitik kaplama, Nikel, Yüzey pürüzlülüğü, Kaplama kalınlığı

\section{Investigation of Coating Thickness and Surface Properties in Electrolithic Ni Coating of 2842, MS58 and Al 6013 Materials}

\begin{abstract}
In this study, the effect of 2842, MS58 ve Al 6013 materials on electroplate Ni coating and the change of surface roughness after coating were investigated. In the experiments, Ç 2842 steel, MS 58 brass and Al 6013 aluminum alloy materials are coated with $\mathrm{Ni}$. These materials were turned at different feed rates $(0,065-0,13 \mathrm{~mm} / \mathrm{rev})$ by lathe and different surface roughness were obtained on the samples. Then the samples were coated with $\mathrm{Ni}$. After the coating process, coating thickness and surface roughness were measured. Visual examinations were made and coating quality was examined. As a result of the experiments, a thicker Ni layer $(43 \mu \mathrm{m})$ was obtained on the MS 58 material according to other materials. The high electrical conductivity of the coated material increases the coating speed. However, the low conductivity value improves the quality of the coating surface. The surface roughness value of the steel
\end{abstract}

*Sorumlu yazar (Corresponding author): Harun KOÇAK, harunkocak@gazi.edu.tr 
material has decreased in the range of $33-57 \%$ thanks to the coating. In $\mathrm{Al} 6013$ material, surface roughness was increased in rate of $94-107 \%$ after coating, at the same time superficial defects in the form of pits occured.

Keywords: Electroplating, Nickel, Surface roughness, Coating thickness

\section{GİRiş}

Elektrolitik kaplama, malzemelerin görünümünü veya yüzeysel özelliklerini geliştirmek için bir substrat üzerine metal tabakası biriktirme işlemdir $[1,2]$. Bu yöntemde kaplama işlemi elektrolitik sıvı(kaplama banyosu) içerisinde yapılmaktadır. Elektrik akımı pozitif yüklü anot ve negatif yüklü katot olarak isimlendirilen iki elektrot arasında cereyan eder. Kaplama olarak uygulanacak metal anot olarak üzeri kaplanan malzeme de katot olarak devreye bağlanır. Elektrik enerjisi, redresör gibi bir DC güç kaynağı tarafından sağlanır. Sisteme enerji sağlandığında elektrolitik sıvı içerisinde bulunan metal iyonları katotta bulunan parça yüzeyine çekilir. Sonra yüzey boyunca gelişeceği noktaya doğru hareket eder ve metal kafesinin içine dâhil olur [3].

Elektrolitik Ni kaplama yöntemi dekoratif amaçlı veya mühendislik uygulamalarında metalik malzemelerin yüzeysel özelliklerini geliştirmek için kullanılmaktadır [4]. Diğer kaplama yöntemlerine göre daha ekonomik bir yöntemdir [5]. Dekoratif amaçlı yapılan kaplamalar daha iyi bir görünümün elde etmek için yapılsa da mühendislik uygulamaları için yapılan kaplamalar genel olarak korozyon ve aşınma direnci arttırmak için uygulanmaktadır [6]. Özellikle otomotiv endüstrisinde nikel kaplama yaygın bir kullanım alanına sahiptir [7-9].

Kaplama işlemlerinde kaplama kalitesi ve Nikel tabakasının yapısı, banyo sıcaklığı, akım yoğunluğu, kaplanacak yüzeyin pürüzlüğü vb. faktörlere bağlı olarak değişir. Nikel tabakasının sertlik, elastisite modülü, mukavemet ve aşınma direnci gibi özellikleri banyo tipi, katkı maddeleri ve elektroliz koşullarına bağlıdır [10]. Çelik üzerine yapılan nikel kaplama tabakasının kalınlığının artması ile kaplama tabakasının atma ihtimalinin arttığı bulunmuştur [11].
Bu çalışmada Ç2842 çelik, MS58 pirinç ve Al 6013 alüminyum alaşımı malzemelerin elektrolitik yöntemle $\mathrm{Ni}$ kaplanması araştırılmıştır. $\mathrm{Bu}$ malzemeler, torna tezgahında farklı ilerleme oranlarında işlenerek numuneler üzerinde farklı yüzey pürüzlülükleri elde edilmiştir. Daha sonra numuneler üzerine $\mathrm{Ni}$ kaplanmıştır. Kaplama işlemi sonrasında kaplama kalınlığı ve kaplama sonrası yüzey pürüzlülüğü ölçülmüş görüntülü incelmeler yapılarak kaplama kalitesi araştırılmıştır.

\section{MATERYAL VE METOT}

\subsection{Malzeme ve Numunelerin Hazırlanması}

Bu çalışmada Ç2842 çelik, MS 58 pirinç ve Al 6013 malzemeler kullanılmıştır. Malzemelere ait kimyasal bileşim Çizelge 1'de verilmiştir. Kaplama işlemlerinde kullanılan $\mathrm{Ni}$ kaplama banyosu Teknik Döküm firmasından hazır olarak alınmıştır.

Çizelge 1. Malzemelerin kimyasal içeriği

\begin{tabular}{|l|l|l|l|l|l|}
\hline \multicolumn{2}{|c|}{ Ç2842 } & \multicolumn{2}{c|}{ MS58 } & \multicolumn{2}{c|}{$\mathrm{Al} 6013$} \\
\hline $\mathrm{C}$ & $0,8-0,9$ & $\mathrm{Cu}$ & 58 & $\mathrm{Cu}$ & $0,6-1,1$ \\
\hline $\mathrm{Si}$ & $0,1-0,4$ & $\mathrm{~Pb}$ & $2,4-2,6$ & $\mathrm{Mg}$ & $0,8-1,2$ \\
\hline $\mathrm{Mn}$ & $1,9-2,1$ & $\mathrm{Zn}$ & kalan & $\mathrm{Zn}$ & 0,25 \\
\hline $\mathrm{Cr}$ & $0,2-0,5$ & $\mathrm{Fe}$ & $0,4-0,6$ & $\mathrm{Fe}$ & 0,5 \\
\hline $\mathrm{V}$ & 0,1 & $\mathrm{Ni}$ & $0,5-0,6$ & $\mathrm{Cr}$ & 0,1 \\
\hline $\mathrm{Fe}$ & kalan & $\mathrm{Sn}$ & $0,4-0,5$ & $\mathrm{Mn}$ & $0,2-0,8$ \\
\hline & & $\mathrm{Al}$ & $0,1-0,2$ & $\mathrm{Si}$ & $0,6-1$ \\
\hline & & & & $\mathrm{Ti}$ & 0,1 \\
\hline & & & & $\mathrm{Al}$ & kalan \\
\hline
\end{tabular}

Kaplama öncesi ve sonrası yüzey pürüzlülüğü değerlerindeki değişimlerin gözlenebilmesi için numuneler torna tezgahıyla işlenerek farklı pürüzlülükler oluşturulmuştur. Pürüzlülük değerlerinin 1-2 $\mu \mathrm{m} / 2-3 \mu \mathrm{m}$ aralıklarında olmak üzere iki farklı değerde olması planlanmıştır. Bunun için Eş 1'den yararlanılarak istenilen yüzey 
pürüzlülüğünün elde edilmesi için torna tezgahının ilerleme miktarı hesaplanmıştır (Eşitlik 1).

$$
\mathrm{Ra}=\frac{\mathrm{fn}^{2}}{8 \mathrm{r}} \times 1000
$$

Malzemeler torna tezgahında farklı ilerleme hızlarında işlenerek $12 \mathrm{~mm}$ çapına ve $40 \mathrm{~mm}$ boyuna getirilerek işlenmiştir.

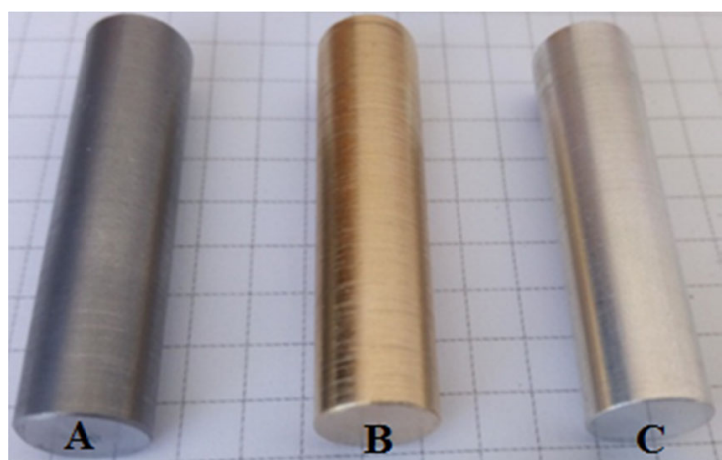

Şekil 1. Numuneler (a: Ç2842, b: MS58, c: Al 6013)

\subsection{Kaplama İșlemleri}

Kaplama işlemleri Şekil 2'de görülen sicaklık kontrollü kaplama sisteminde yapılmıştır. $\mathrm{Bu}$ sistemde alttaki büyük kap içerisinde bulunan su, 1sitıcı rezistans sayesinde 1sitılmakta ve isınan suyla birlikte üstteki küçük kap içerisinde yer alan $\mathrm{Ni}$ kaplama banyosu 1sitilmaktadir. Sistemde bulunan termostat sayesinde sicaklık kontrolü sağlanmaktadır.

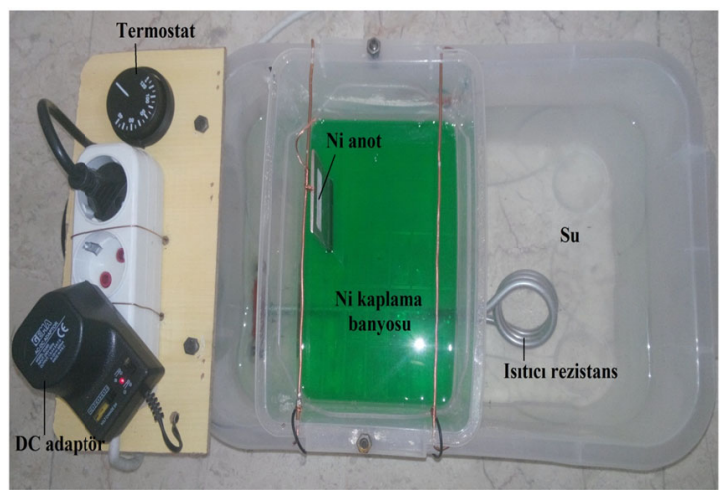

Şekil 2. Kaplama sistemi
Kaplama işleminde teknik döküm firmasından hazır olarak alınan $\mathrm{Ni}$ kaplama banyosu kullanılmıştır. Kaplama işlemi standart oluşturmak için Çizelge 2'de verilen şartlarda yapılmıştır. Kaplama işlemlerinde $\mathrm{pH}$ değerinin değişmesinden kaynaklanacak etkileri en aza indirmek için her bir kaplama işleminde kaplama banyosu değiştirilmiştir. Kaplama işlemi sonrası kaplama kalınlığı 1/1000 hassasiyetinde mikrometre kullanılarak çap yüzeyinden ölçülmüştür.

Çizelge 2. Elektrolitik Ni kaplama şartları

\begin{tabular}{|c|c|c|c|c|}
\hline $\begin{array}{l}\overrightarrow{0} \\
\stackrel{3}{4}\end{array}$ & 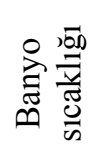 & $\begin{array}{l}\frac{\pi}{5} \\
>\end{array}$ & छ & 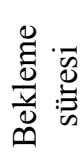 \\
\hline 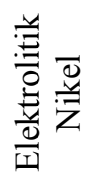 & $\begin{array}{l}0 \\
0 \\
0 \\
0 \\
1 \\
0 \\
n\end{array}$ & 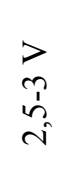 & $\frac{\mathfrak{Z}}{\grave{Z}}$ & 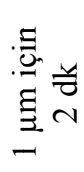 \\
\hline
\end{tabular}

\subsection{Yüzeysel Özelliklerin İncelenmesi}

Kaplama işlemi öncesinde ve sonrasında numunelerin yüzey pürüzlülüğü değerleri ölçülmüştür. Yüzey pürüzllülüğü ölçümünde Mitutoya SJ-210 pürüzlülük cihazı kullanılmıştır. Üç farklı bölgeden ölçüm yapılarak ortalama yüzey pürüzlülüğü değeri (Ra) bulunmuştur. Kaplama yüzeyleri mikroskop yardımıyla incelenerek yüzeysel hatalar araştırılmıştır.

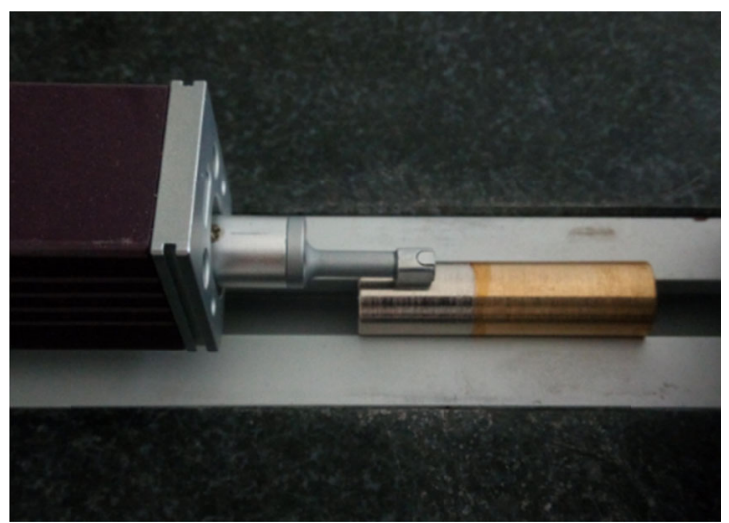

Şekil 3. Yüzey pürüzlülüğü ölçümü 


\section{SONUÇLAR VE TARTIŞMA}

\subsection{Kaplama Kalınlığı}

Kaplama işlemi 40 dakika sürede yapılarak numunelerin uç kısmı $15 \mathrm{~mm}$ uzunlukta kaplanmıştır. Kaplama sonrası mikrometre yardımıyla kaplama kalınlığı ölçülmüştür. Ölçülen kaplama değerleri Şekil 4'te verilmiş̧ir. Kalınlık değerleri karşılaştırıldığında MS 58 malzemenin en yüksek olarak $43 \mu \mathrm{m}$, sonrasında Al 6013 malzemenin $40 \mu \mathrm{m}$ ve Ç2842 malzemenin $35 \mu \mathrm{m}$ kaplandığı görülmüştür. Bütün numuneler eşit sürede ve aynı şartlarda kaplanmasına rağmen MS 58 malzeme üzerinde daha kalın Ni tabakası oluşmuştur.

Elektrolitik Ni kaplama işlemini banyo sıcaklığı, akım yoğunluğu, kaplanacak yüzeyin pürüzlüğü vb. gibi faktörler etkilemektedir [10]. Ancak bu faktörler olabildiğince sabit tutulmaya çalışılmış ve kaplama işlemleri aynı şartlarda yapılmıştır. Kaplama kalınlığında ortaya çıkan bu farkın malzemelerin fiziksel özelliklerinden dolayı kaynaklandığı tahmin edilmektedir.

Malzemelerin elektriksel iletkenlikleri karşılaştırıldığında Al 6013 alaşımının 37-39 $\mathrm{S} / \mathrm{m}^{*} 10^{6}[12]$, MS 58 pirinç malzemenin 14-16 S/m*10 $0^{6}[13]$ ve Ç2842 çelik malzemenin 2-6 $\mathrm{S} / \mathrm{m}^{*} 10^{6} \quad$ [14] olduğu görülmüştür. Malzemelerin elektriksel iletkenliğinin yüksek olması anot-katot arasında iletimi arttırdığı ve bu sayede birim zamanda elde edilen kaplama kalınlığının arttığ d düşünülmektedir. Ancak bu değerler göz önüne alındığında en yüksek kalınlığın Al 6013 malzemede meydana gelmesi beklenirken MS 58 malzemede ölçülen kaplama kalınlığı daha fazladır.

Alüminyum malzeme doğal bir özelliği olarak havaya maruz kaldığında yüzeyinde ince oksit tabakası olușmaktadır [15]. Malzemeler üzerinde oluşan oksit tabakaları iletkenliği olumsuz olarak etkilemektedir [16]. $\mathrm{Bu}$ nedenle $\mathrm{Al}$ malzeme üzerinde oluşan oksit tabakası elektriksel iletkenliği düşürdüğü için buna bağglı olarak $\mathrm{Al}$ malzemede oluşan kaplama kalınlığı da MS 58 malzemeden daha düşüktür.

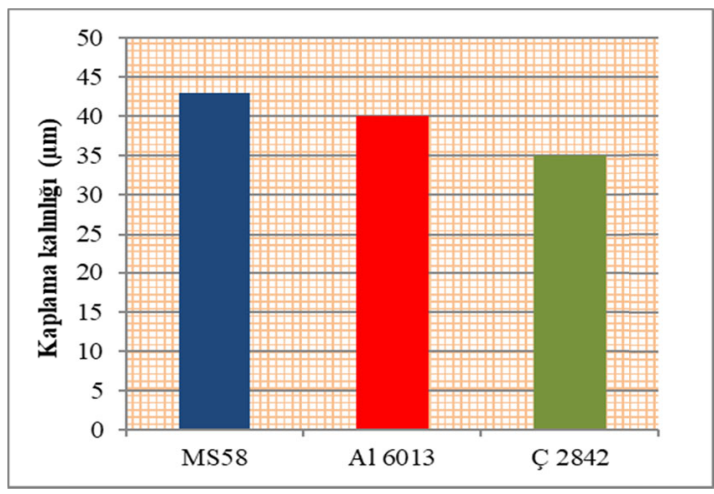

Şekil 4. Kaplama kalınlığ

\subsection{Yüzey Pürüzlülüğü Değișimi}

Numuneler iki farklı ilerleme $(0,065-0,13 \mathrm{~mm} / \mathrm{dev})$ değerinde işlenerek farklı pürüzlülükler oluşturulmuştur. Daha sonra numunelere $\mathrm{Ni}$ kaplama işlemi yapılarak ve kaplama sonrası yüzey pürüzlülüğü değişimleri incelenmiştir. Yüzey pürüzlülüğündeki değișimler Şekil 5 ve Şekil 6'da görülmektedir. Şekil 5 incelendiğinde MS58 numunede kaplama öncesi 2,11 $\mu \mathrm{m}$ olan yüzey pürüzlülüğünün $1,89 \mu \mathrm{m}$ değerine düştüğü görülmüştür. Benzer şekilde Ç2842 çelik numunede de kaplama sonrası yüzey pürüzlülüğü değeri azalarak 1,46 $\mu \mathrm{m}$ 'dan $0,62 \mu \mathrm{m}$ değerine düşmüştür. Çelik malzemede kaplama sonras1 yüzey pürüzlülüğü Şekil 5 'te yer alan değerlere göre \%57 Şekil 6'da ki değerlere göre de \%33 azalmıştır. Çelik malzemede yüzey pürüzlülüğü değeri kaplama sonrası MS58 malzemeden daha fazla azalmıştır.

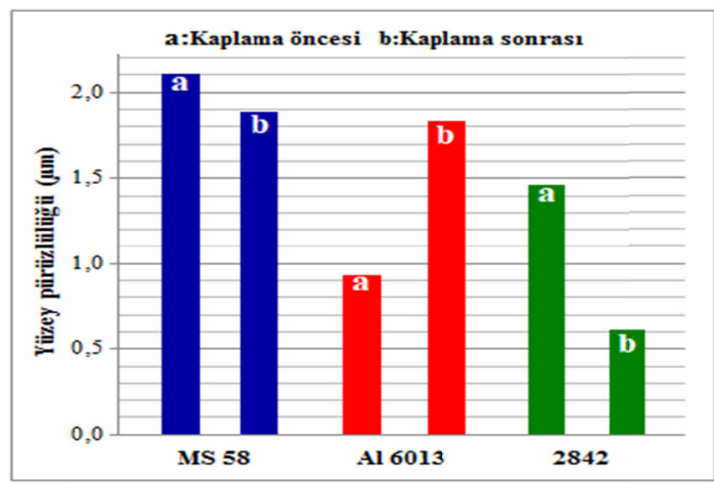

Şekil 5. Yüzey pürüzlülüğü değerleri (f: 0,065 $\mathrm{mm} / \mathrm{dev}$ ilerlemede işlenen numuneler) 
Al 6013 malzemenin kaplama sonrası yüzey pürüzlülüğü incelendiğinde diğer malzemelere zıt olarak arttığı tespit edilmiştir. Şekil 5'te görüldüğü gibi Al 6013 numunede kaplama öncesi yüzey pürüzlülüğü değeri $0,94 \mu \mathrm{m}$ iken kaplama sonrası artış meydana gelmiş ve pürüzlülük değeri $1,83 \mu \mathrm{m}$ olmuştur. Şekil 6'da da yine yüzey pürüzlülüğü artarak 1,46 $\mu \mathrm{m}$ 'dan 3,03 $\mu \mathrm{m}$ değerine çıkmıştır. Al 6013 malzemenin kaplama öncesi ve sonrası yüzey pürüzlülüğü değerleri kıyaslandığında yaklaşık olarak \%50 artış meydana geldiği söylenebilir.

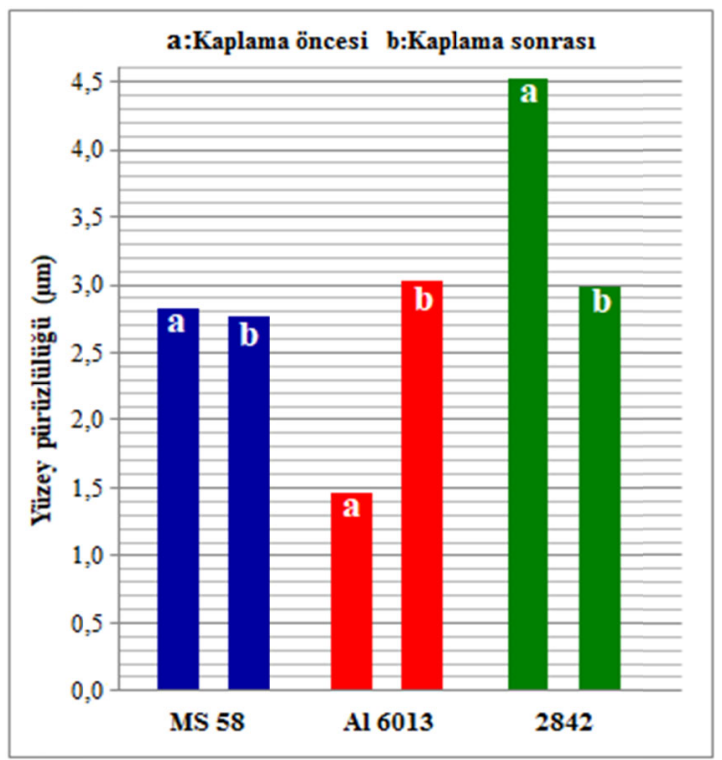

Şekil 6. Yüzey pürüzlülüğü değerleri (f:0,13 $\mathrm{mm} / \mathrm{dev}$ ilerlemede işlenen numuneler)

Yüzey pürüzlülüğü malzemelerin yorulma direnci ve aşınma dayanımı gibi özellikleri etkilediği $[17,18]$ için önemli bir faktördür ve kaplama işlemlerinde pürüzlülük azaltılmaya çalışılmaktadır. Deneylerde kullanılan bütün malzemeler incelendiğinde yüzey pürüzlülügüünün azalması bakımından en iyi sonuç çelik malzemede alındığ 1 tespit edilmiştir. Bu sonucun da malzeme özelliklerine bağlı olarak ortaya çıktığ düşünülmektedir. Elektrolitik kaplamada kaplama kalitesini etkileyen en önemli bir parametre akım değeridir ve bu değer yüksek olduğunda yüzeysel hatalar ortaya çıkmaktadır [19]. Her bir malzeme aynı sistemde kaplanmasına rağmen böyle bir sonucun ortaya çıkması çelik malzemenin elektriksel iletkenliğinin diğer malzemelerden daha düşük olmasıyla açıklanabilir. İletkenliğin düşük olmasıyla daha dirençli bir kaplama işlemi söz konusu olmakta ve yüzey pürü:zlülügünü oluşturan girinti çıkıntılarda bütün yüzey boyunca daha düzgün bir kaplama birikintisi elde edilmektedir. $\mathrm{Bu}$ nedenle çelik malzemedie kaplama sonrası pürüzlülük değeri diğer malzemelerden daha fazla azalmıştır (Şekil 5).

\subsection{Kaplama Yüzeyinin İncelenmesi}

Kaplama işlemlerinde malzemelerin korozyon direncinin arttırılmasının yanında istenilen bir özellik te dış görünümün iyileştirilmesidir [20]. Bu nedenle kaplama işlemleri nümkün olduğunca optimum parametrelerde yapılırsa yüzey görünümü de iyileşmektedir. Yapılan deneylerde hazır kaplama banyosu alınmış ve kaplama işlemleri optimum parametrelerde yapılmıştır. Çelik ve MS58 malzemelerin kaplanmasinda yüzeysel hataların ortaya çıkmamasıyla birlikte yüzey pürüzlülüğü değerlerinin de azaldığı belirlenmiştir (Şekil 7 ve Şekil 8). Bu istenilen bir sonuçtur. Ancak Al 6013 malzemenin kaplanma sonras1 yüzey pürüzlülüğü artmakla beraber yüzeysel hatalar da ortaya çıktığı Şekil 9'da görülmektedir. Şekil 9 incelendiğinde yüzeydle çukurlar şeklinde hatalar oluştuğu görülmüştür. Yüzey pürüzlülüğü daha fazla olan numune kaplandığında ise oluşan çukurlar (Şekil 9b) büyümektedir. Sadece Al 6013 malzemede böyle bir durumun ortaya çıkması yüzey oksitlerinin bazı bölgelerde malzeme yüzeyini yalıtkan hale getirerek $[15,16]$ o bölgelerin kaplamaya engel teşkil etmesiyle açıklanabilir.

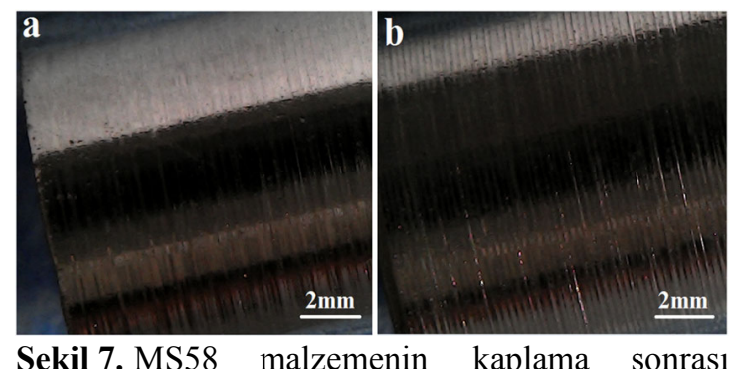

Şekil 7. MS58 malzemenin kaplama sonrası yüzeyi, (a: 0,065 mm/dev, Ra: 1,89 $\mu \mathrm{m}$, b: $0,13 \mathrm{~mm} / \mathrm{dev}$, Ra: $2,76 \mu \mathrm{m})$ 
Ç2842, MS58 ve Al 6013 Malzemelerin Elektolitik Ni Kaplanmasında Kaplama Kalınlı̆̆ ve Yüzeysel Özelliklerin İncelenmesi

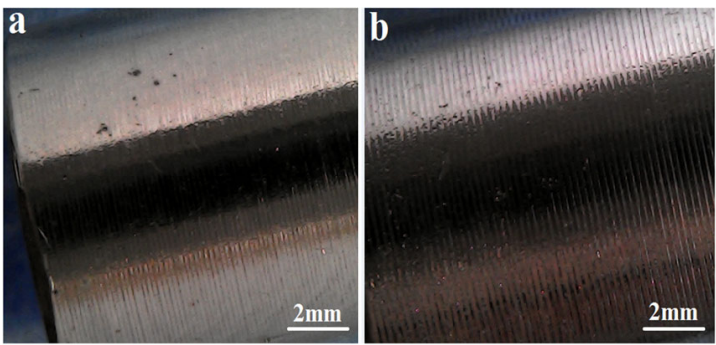

Şekil 8. Ç2842 malzemenin kaplama sonrası yüzeyi (a: $0,065 \mathrm{~mm} / \mathrm{dev}$, Ra: $0,62 \mu \mathrm{m}$, b: $0,13 \mathrm{~mm} / \mathrm{dev}$, Ra: $2,99 \mu \mathrm{m})$
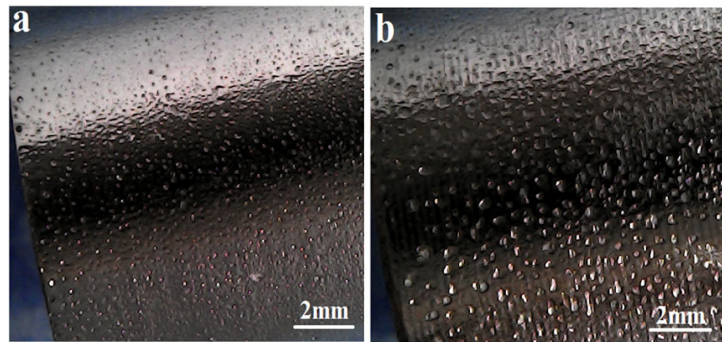

Şekil 9. Al6013 malzemenin kaplama sonrası yüzeyi (a: $0,065 \mathrm{~mm} / \mathrm{dev}$, Ra: $1,83 \mu \mathrm{m}$, b: $0,13 \mathrm{~mm} / \mathrm{dev}, \mathrm{Ra}: 3,03 \mu \mathrm{m})$

\section{SONUÇLAR}

Bütün numuneler eşit sürede ve aynı şartlarda kaplanmasına rağmen MS 58 malzeme üzerinde daha kalın Ni tabakası elde edilmiştir. Kaplanan malzemenin elektriksel iletkenliğinin yüksek olması kaplama hızını artırdığı belirlenmiştir. Ancak, iletkenlik değerinin düşük olması kaplama yüzeyinin kalitesini iyileştirmektedir. Bu nedenle çelik malzemenin iletkenlik değeri daha düşük olduğu için kaplama sonrası yüzey pürüzlülüğü değeri diğer malzemelere kiyasla daha fazla azalmıştır. Çelik malzemenin kaplama sayesinde yüzey pürüzlülüğü değeri \%33-57 aralığında azalmıştır. Al 6013 malzemede kaplanma sonrası yüzey pürüzlülüğü artmakla beraber yüzeysel hatalar da ortaya çıkmıştır. Al 6013 malzemenin iletkenlik değerinin yüksek olmasıyla beraber yüzey oksitleri, kaplamamın yüzey kalitesini düşürmektedir.

\section{KAYNAKLAR}

1. Rose, I., Whittington, C., 2002. Nickel Plating Handbook, OM Group, Espoo, Finland.

2. Kaya, B., 2007. Nano Kompozit Kaplama, Yüksek Lisans Tezi, İTÜ Fen Bilimleri Enstitüsü, İstanbul, 117.

3. Riedel, W., 1991. Electroless Nickel Plating, ASM International Metals Park, Ohio, USA.

4. İnternet: $\mathrm{Ni}$ Plating Handbook. URL: https://nickelinstitute.org/media/2323/nph_141 015.pdf, Son erişim tarihi: 31.10.2020.

5. Borisenko, N., Zein El Abedin, S., Endres, F., 2017. Electrodeposition from Ionic Liquids. Electrodeposition from Ionic Liquids. Wiley, doi: 10.1002/9783527622917.

6. TS ISO 4526, Metalik Kaplamalar-mühendislik amaçl1-elektrolitik Nikel Kaplamalar, Nisan1999.

7. Hou, K.H., Ger, M.D., Wang, L.M. 2002. The Wear Behavior of Electro-codeposited Ni-SiC Composites, Wear, 253, 994-1003.

8. Wang, S.C., Wei, W.C.J., 2003. Kinetics of Electroplating Process of Nano-sized Ceramic Particle/Ni Composite, Mater. Chem. Phys. 78, 574-580.

9. Chen, L., Wang, L., Zeng, Z., Zhang, J., 2006. Effect of Surfactant on the Electrodeposition and Wear Resistance of $\mathrm{Ni}-\mathrm{Al}_{2} \mathrm{O}_{3}$ Composite Coatings, Mater. Sci. Eng. A 434, 319-325.

10. Kortman, W., 1986. En Çok Uygulanan Yüzey İşlemleri-karşılaştırmalı bïr Bakış, Çeviren: Yüksel, M., Metalurji Dergisi, 44, 13-25.

11. Chan, K.C., Wang, S.H., 2001. The Effect of a Coatings on the Springback of Integrated Circuit Leadframes, Journal of Materials Processing Technology, 116, 231-234.

12. SAE International Group, 2009. Hardness and Conductivity Inspection of Wrought Aluminum Alloy Parts, Aerospace Material Specification AMS2658B, 2009-10.

13. İnternet: Malzemelerin İletkenli Değerleri, URL:http://wiki.robotz.com/index.php?title=El ectrical_Conductivity_of_Various_Metals, Son erişim tarihi: 31.10 .2020 .

14. İnternet: Malzemelerin İletkenli Değerleri, URL:http://kocwn.xcache.kinxcdn.com/data/do 
cument/2017/chonnam/johnfisher053/3.pdf,

Son erişim tarihi: 31.10 .2020

15. Ateş, S., Mutlu, R.N., Mert, B.D., Yazıcı, B., 2017. Etilen Glikol+ Sülfürik Asit İçerisinde 7075 Aluminyum Alaşımı Üzerinde Aluminyum Oksit Tabakasının Geliştirilmesi. Engineering Sciences, 12(2), 123-132.

16. İnternet: Elektriksel Temas Direnci Üzerindeki Olumsuz Etkiler, URL: http://sarkuysan.com/ Upload/Document/document_ff1655bcd7d34ca 08a2f23c864b7c20f.pdf, Son erişim tarihi: 31.10.2020.

17. Çetin, M., Bilgin, M., Ulaş, H.B., Tandıroğlu, A., 2011. Kaplamasız Sermet Takımla Ais1 6150 Çeliğinin Frezelenmesinde Kesme Parametrelerinin Yüzey Pürüzlülüğüne Etkisi. Ejovoc (Electronic Journal of Vocational Colleges), 1(1), 168-176.

18. Özdemir, M., 2019. Optimization with Taguchi Method of Influences on Surface Roughness of Cutting Parameters in CNC Turning Processing. Mechanics, 25(5), 397-405.

19. Alp, A., 2016. Elektrolitik Metal Kaplama Ders Notları, SAÜ Müh. Fak. Metalurji ve Malzeme Müh.Böl., https://docplayer.biz.tr/18034369Elektrolitik-metal-kaplama.html.

20. Laçin, M.K., 2003. Elektrolitik Kaplamanın Günlük Hayatımızdaki Yeri, Yüzey İşlemler, 36(6), 4-6. 
